\title{
Brief encounter
}

\section{John Launer}

While sitting near the boarding gate with my family at an international airport, I noticed a young man and woman opposite me. Both were in their twenties. I assumed they were flying back home together to London, at the end of their summer vacation. After several minutes neither had spoken and I realised they were strangers, although they looked as if they would make a suitable match. For a moment, I had the ridiculous thought of suggesting they should talk to each other. Such thoughts don't come into one's mind for no reason, and when the man got up to join the queue for the plane, I noticed the woman look up and follow him wistfully with her eyes. Seeing me watching her, she smiled slightly and blushed. I wondered if she would now try and stand behind him in line and strike up a conversation after all. However, by the time she joined the queue, a large family had beaten her to it. There would be no conversation, nor the relationship that might have followed. I felt for the young woman. Most of us have no doubt been in the same position as her at some time-too shy to talk to someone we wanted to. But it also struck me what a good illustration the episode was of some fundamental principles of evolutionary psychology.

It was Darwin who first suggested that we should examine all human behaviour and feelings in the light of the drive for reproduction, and the challenges it raises. No one took up his suggestion in any systematic way for a hundred years. However, the field of evolutionary psychology is finally coming into its own and beginning to equip us with the knowledge to 'read' encounters like this, and many others, just as we would with primates or other mammals. Drawing on the ideas of evolutionary scholars like David Buss, ${ }^{1}$ Robin Dunbar ${ }^{2}$ and Christopher Boehm, ${ }^{3}$ I want to propose a way of deciphering the little mini-drama that I witnessed.

\section{SEEKING A MATE}

Homo sapiens, as Darwin realised, is no different from any other sexually

Correspondence to Dr John Launer, London Deanery, Stewart House, London WC1B 5DN, UK;

jlauner@londondeanery.ac.uk reproducing species on the planet. Our overriding imperative is to reproduce-or to support our kinship group in doing so. If we want to make a direct contribution through having progeny ourselves, we need to do this during our years of maximum fertility, which for women happens to be during late adolescence and early adulthood. If it wasn't for the drive for reproduction, we wouldn't experience desire, and without desire the young woman at the airport would never have been interested in the man next to her.

Desire has to fix on the best available person at any given time and place. It is no use if you are in the arrivals area when a potential partner of the opposite sex is at the boarding gate. In that respect, you are no different from a wild flower that is never fertilised with pollen from a particular plant in a neighbouring field because the bee has flown off elsewhere. Outside romantic novels, very few people live their lives entirely free of desire until the one and only Mr Right or Ms Right comes on the scene. Our species would not have lasted very long if that had been the case. It is better to feel desire for someone who happens to cross your path in good time-or whoever sits down in the chair next to you at the airport-rather than waiting for something that will never happen.

Having said that, desire is still highly selective. While on the alert for reproductive opportunities, everyone also instantaneously assesses others for their suitability as reproductive mates. This is presumably why the young woman in question was drawn instinctively towards the equally young and attractive man beside her rather than the considerably older greyhaired family man (myself) sitting opposite. She didn't need a checklist to work out that the younger man might fit a number of categories for a better match. In the same way, I intuitively recognised the two of them as a potential mating pair if not an actual one.

\section{OPPORTUNITIES AND RISKS}

Desire is selective, but it is also contextual. As it happens, airports and other places of transit seem to be particularly good places to stimulate sexual attraction, for all sorts of reasons. Away from their familiar networks, people are deprived of the everyday comforts that might distract them from seeking a partner, but also free from the social judgements that might inhibit a liaison. It is no coincidence that stories of holiday romances and affairs with transient foreigners are so common.

In addition, desire is always accompanied by risk. It is in this area that evolutionary thinking may help us the most in deciphering the incident I witnessed. Although the young woman at the airport may have longed for the man to turn to her and engage in conversation, an intuitive assessment of risk seemingly led her to feel she couldn't take the initiative herself. As a woman, she was far from unusual in making this judgement-and for good reasons. Women carry far more risks to physical and personal safety than men do. These include not only the dangers of pregnancy and childbirth but also rejection, abuse, abandonment and worse. All of this is presumably why, across all cultures, it is hugely more common for men of all ages and appearances to make sexual advances than for attractive young women to do so.

\section{UNSPOKEN COMMUNICATION}

Perhaps the most interesting aspect of this episode was the unspoken communication that took place between the woman and myself. Firstly there was that strange, almost telepathic contact that led me to have the weird fantasy of effecting an introduction between them. Such 'psychic' moments are not as bizarre as they may seem. We pick up people's intentions from the way they look and from their body language, and this in turn affects our thoughts without us even being aware this has happened, a process that some people call 'mentalisation'. As for her smile and blushing-a phenomenon that Darwin discovered is universal in our species, and unique to us alone-it disclosed her discomfort at having unwittingly displayed her private desires: something we simply aren't meant to do as we carry out our carefully concealed reproductive strategies.

Medical students are taught little or nothing about the theory of evolution. Most doctors will have read nothing about evolutionary psychology or even perhaps have heard of it. This is a great pity. As a framework for thinking about human interactions, it makes a good deal of sense. It is surprisingly simple, and is intrinsically fascinating. The airport episode shows its potential for 
understanding how we behave in everyday life, how we feel, and who we are.

Competing interests None.

Provenance and peer review Commissioned: internally peer reviewed.
Postgrad Med J 2012:88:615-616.

doi:10.1136/postgradmedj-2012-131423

\section{REFERENCES}

1. Buss D. The evolution of desire: strategies of human mating. New York: Basic Books, 1993.
2. Dunbar R, Barrett L, Lycett J. Evolutionary psychology: a beginner's guide. Oxford: One World Books, 2005.

3. Boehm C. Moral origins: the evolution of virtue, altruism and shame. New York: Basic Books, 2012 